\title{
Association of Socioeconomic Status and Overweight/Obesity in Rural-to-Urban Migrants: Different Effects by Age at Arrival
}

\author{
Ye Wang ${ }^{1}$, Li Pan ${ }^{1}$, Shaoping Wan ${ }^{2}$, Huowuli Yi ${ }^{3}$, Fang Yang ${ }^{4}$, Huijing He ${ }^{1}$, Zheng $\mathrm{Li}^{4}$, \\ Zhengping Yong ${ }^{5}$ and Guangliang Shan ${ }^{1 *}$ \\ ${ }^{1}$ Department of Epidemiology and Statistics, School of Basic Medicine, Institute of Basic Medical Sciences, Chinese \\ Academy of Medical Sciences, Peking Union Medical College, Beijing, China, ${ }^{2}$ Sichuan Cancer Center, School of Medicine, \\ Sichuan Cancer Hospital and Institute, University of Electronic Science and Technology of China, Chengdu, China, ${ }^{3}$ Puge \\ Center for Disease Control and Prevention, Liangshan, China, ${ }^{4}$ Xichang Center for Disease Control and Prevention, \\ Liangshan, China, ${ }^{5}$ Sichuan Academy of Medical Sciences and Sichuan Provincial People's Hospital, Chengdu, China
}

OPEN ACCESS

Edited by:

Amanda R. Amorim Adegboye, University of Greenwich, United Kingdom

Reviewed by: Débora Martins Dos Santos, Rio de Janeiro State University, Brazi Omorogieva Ojo,

University of Greenwich, United Kingdom

*Correspondence: Guangliang Shan guangliang_shan@163.com

Specialty section: This article was submitted to Life-Course Epidemiology and Social Inequalities in Health, a section of the journal

Frontiers in Public Health

Received: 29 October 2020 Accepted: 30 November 2020 Published: 17 December 2020

Citation:

Wang $Y$, Pan L, Wan $S, Y i H$, Yang $F$, He H, Li Z, Yong Z and Shan G (2020) Association of Socioeconomic Status and Overweight/Obesity in

Rural-to-Urban Migrants: Different Effects by Age at Arrival.

Front. Public Health 8:622941.

doi: 10.3389/fpubh.2020.622941
This study aims to investigate the association between socioeconomic status and overweight/obesity in rural-to-urban Yi migrants in China, and to explore whether the association varied by the age at arriving urban areas. The cross-sectional population-based data from the Yi Migrants Study in 2015 was used, which included 1,181 Yi migrants aged 20-80 years. Socioeconomic status was evaluated by education level, personal annual income, and a composited variable (socioeconomic status index, SESI). Measured weight and height were used to calculate BMI and to define overweight/obesity $\left(\mathrm{BMl} \geq 24 \mathrm{~kg} / \mathrm{m}^{2}\right)$. The results suggested that the association of income and SESI with overweight/obesity was not significant when age at arrival (two groups, $<20$ and $\geq 20$ years) was considered as a covariate. In the stratification analysis, reversed association was observed in the two groups of age at arrival. In migrants of $<20$ years of age at arrival, higher level of education and SESI were related to decreased risk of overweight/obesity. In contrary, in those of $\geq 20$ years at arrival, higher socioeconomic status level was found to be related to increased risk. Our findings suggest that the effect of socioeconomic status on overweight/obesity was modified by the age at arrival in Yi migrants. Especially, the association between socioeconomic status and overweight/obesity was negative when migration before 20 years of age, and transfer to positive after 20 years.

Keywords: overweight, obesity, socioeconomic, China, Yi migrant

\section{INTRODUCTION}

Obesity is a fast-growing public health problem that has raised worldwide concern. The prevalence of overweight and obesity in the past decades has reached epidemic proportions in many countries (1). Obesity is not only defined as a chronic disease, but also substantially increases the risk of metabolic diseases, cardiovascular diseases, and some types of cancer (2). The World health organization (WHO) defines obesity as excessive fat accumulation that might impair health. It is recognized that obesity is the result of the interplay between comprehensive factors including genetic and environmental determinants (3). 
Socioeconomic status (SES) has been identified as one of the factors that related to obesity. But recent updates demonstrated inconsistent associations across populations. Some evidences from developed countries revealed that low-SES groups were at increased risk of obesity than their high-SES counterparts $(4,5)$. While in low- or middle-income countries, the association became mixed, showing a variation from positive to none or inverse relationship $(6,7)$. Even in China, disparities in the relationship was found across regions, gender, and rural/urban areas $(8,9)$.

Urbanization in China is rapidly proceeding and the scale of rural-to-urban migration is gradually expanding (10). The transition in socioeconomic status and lifestyle patterns in ruralto-urban migrants may lead to increase in risk of obesity, and migration studies provide valuables information on the effects of environment factors transition on health. Yi people is the population settled in isolated mountainous areas in southwest China, and was known as low prevalence of hypertension and obesity. Since the 1950s, some Yi farmers migrated to urban areas for living and working. Previous work of the Yi Migrant Study has well-demonstrated the effects of rural-to-urban migration on chronic diseases (11-13). But the relationship between SES and obesity in Yi migrants is not clear, especially existing the fact that the SES varied by acculturation groups in migrants. Using crosssectional data from the Yi Migrants Study in 2015, this study investigated the association between SES and overweight/obesity in rural-to-urban Yi migrants, and to explore whether the association varied by the age at arrival.

\section{METHODS}

\section{Study Population}

A cross-sectional survey was conducted in April and November 2015 in Liangshan Yi Autonomous Prefecture, Sichuan province, China. The Yi Migrant Study was designed to assess cardiovascular risk factors in rural-to-urban Yi migrants. Details of the sampling procedures have been described previously (14). Briefly, a stratified cluster sampling method was used to select participants aged 20-80 years. In the first stage, the autonomous prefecture capital, Xichang city, and an economic backward area, Puge county were selected. In the second stage, three urban districts in Xichang city and the town with county administration seats in Puge county were selected to enroll Yi migrants. In the final stage, residents in the selected areas were all invited to participate in the survey. In this study, Yi people were identified as individuals whose parents were both of Yi ethnicity. Yi migrants were defined to be Yi people who were born in rural areas and then migrated to urban areas for at least 1 year. All participants provided written informed consent before the survey.

\section{Measurements}

Demographic information, socioeconomic data and lifestyle factors were collected by face to face interviews. The interview was conducted by well-trained medical staff using standard questionnaire. Body height and weight were measured with bared feet and light clothing using fixed stadiometer and body composition analyzer (BC-420, TANITA, Japan), with the accuracy to $0.1 \mathrm{~cm}$ and $0.1 \mathrm{~kg}$, respectively. The average of two height measurements was recorded.

\section{Dependent Variable}

The continuous outcome, body mass index (BMI) was calculated as the weight in kilograms divided by the square of height in meters. The binary variable, overweight/obesity was defined as $\mathrm{BMI} \geq 24 \mathrm{~kg} / \mathrm{m}^{2}$, according to the recommendation suitable for Chinese population (15).

\section{Independent Variables}

The acculturation of Yi migrants was measured through age at arrival and length of residence in urban areas, which represent the extent of exposure to the urban environment. By asking respondents the year and month they first moved from rural to urban areas, the age of arrival and length of residence were calculated according to the birth date, move date, and survey date. Under the consideration of sample size, sample characteristics, and round-off number, age at arrival of the subjects was classified into two groups: $<20$ and $\geq 20$ years, and length of residence was classified as $1-9,10-19$, and $\geq 20$ years.

Socioeconomic status was evaluated by two direct variables: education level and personal annual income, and one compositive variable: socioeconomic status index (SESI). Education was categorized into three categories based on the participants' highest educational attainment: illiterate, primary or middle school (equivalently $<12$ years of education), and high school or above (equivalently $\geq 12$ years of education). Personal annual income was categorized into two groups in accordance with the round-off number of the median $(<20,000$ and $\geq 20,000 \mathrm{CNY} /$ year). SESI was composited by assigning a score to education and income. The assignment was 0 point for illiterate and $<20,000 \mathrm{CNY} /$ year, 1 point for primary or middle school and $\geq 20,000 \mathrm{CNY} /$ year, and 2 points for high school or above. Combining the score for education and income, SESI was categorized as low ( 0 point), middle ( 1 point), and high (2 or 3 points).

Other covariates included were smoking, alcohol drinking, occupational physical activity, and leisure-time exercise. Both smoking and drinking were grouped into current, former, and never. Occupational physical activity was grouped into light, moderate, and heavy according to the intensity of daily work. Leisure-time exercise was considered as participation in moderate or vigorous activity for at least $20 \mathrm{~min}$ at leisure time, with three levels as light ( $<1$ day per week), moderate (1-4 days per week), and heavy (5-7 days per week).

\section{Statistical Analyses}

Descriptive statistics was performed stratified by age at arrival and length of residence. Chi-square test and variance analysis were used for categorical and continuous variables, respectively.

To examine whether there was significant association between socioeconomic status with outcomes, the following modeling strategies were applied. Initially, a linear regression model with $\mathrm{BMI}$ as the outcome and socioeconomic variables as the primary interested variable, while controlling for covariates including age 
TABLE 1 | Characteristics of the study sample by age at arrival and length of residence.

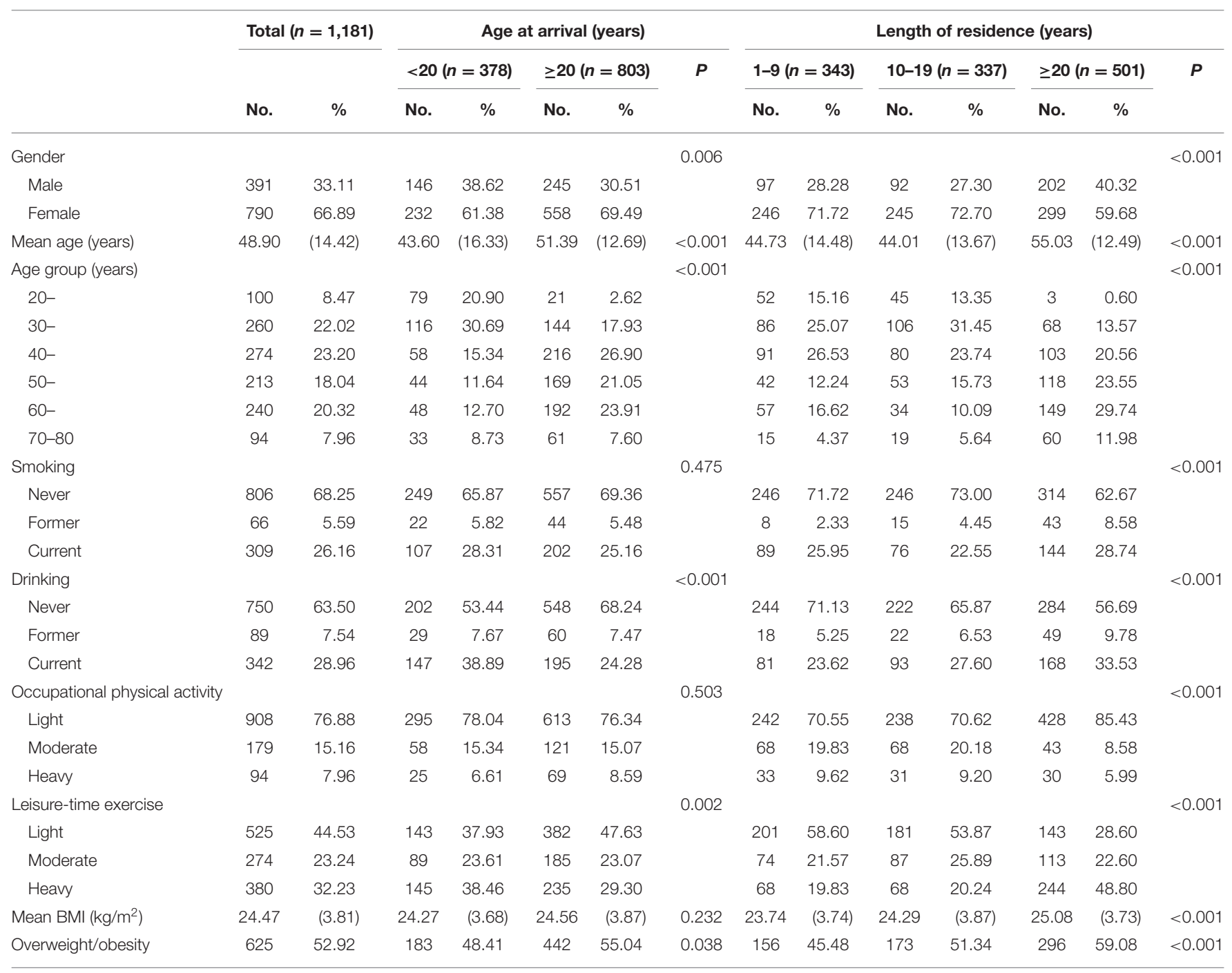

Numbers in parentheses are standard deviation.

at arrival. As SESI was derived from education and income, two separated models were fitted: (a) model included education and income, and (b) model only included SESI. Second, logistic regression models with overweight/obesity as the outcome were used to estimate odds ratio (OR) and 95\% confidence interval (CI) following the above modeling rules. Due to the complex survey design, logistics regression models used took account of the complexity of the stratified cluster sampling strategy (16).

Thereafter, an interaction term was included in the logistic models to test the hypotheses that the association between socioeconomic status and overweight/obesity may be modified by the age at arrival. These three socioeconomic indicators were evaluated independently of each other by including one interaction term at a time. Finally, to determine how the association was differed, logistic regression models were fitted with stratification by age at arrival. We also test the interaction between length of residence and socioeconomic status, but no significant interaction term was found, thus we did no further analysis. All regression analyses were controlled for the following covariates: age (starting at 20 and grouped per 10 years), gender, smoking, drinking, physical activity, exercise, and length of residence.

A two-tailed $p$-value of $<0.05$ was considered statistically significant. All analyses were conducted using SAS statistical software (Version 9.4; SAS Institute Inc., Cary, NC, USA).

\section{RESULTS}

Table 1 lists the characteristics of the study sample of by age at arrival and length of residence. This study included $33.11 \%$ males and $66.89 \%$ females, with the mean age at $48.90 \pm 14.42$ years. Between the two groups of age at arrival, there was significant difference in demographic characteristics. Compared to respondents who were $<20$ years at arrival, migrants of $\geq 20$ years at arrival had older age, were less likely to drink, and less 

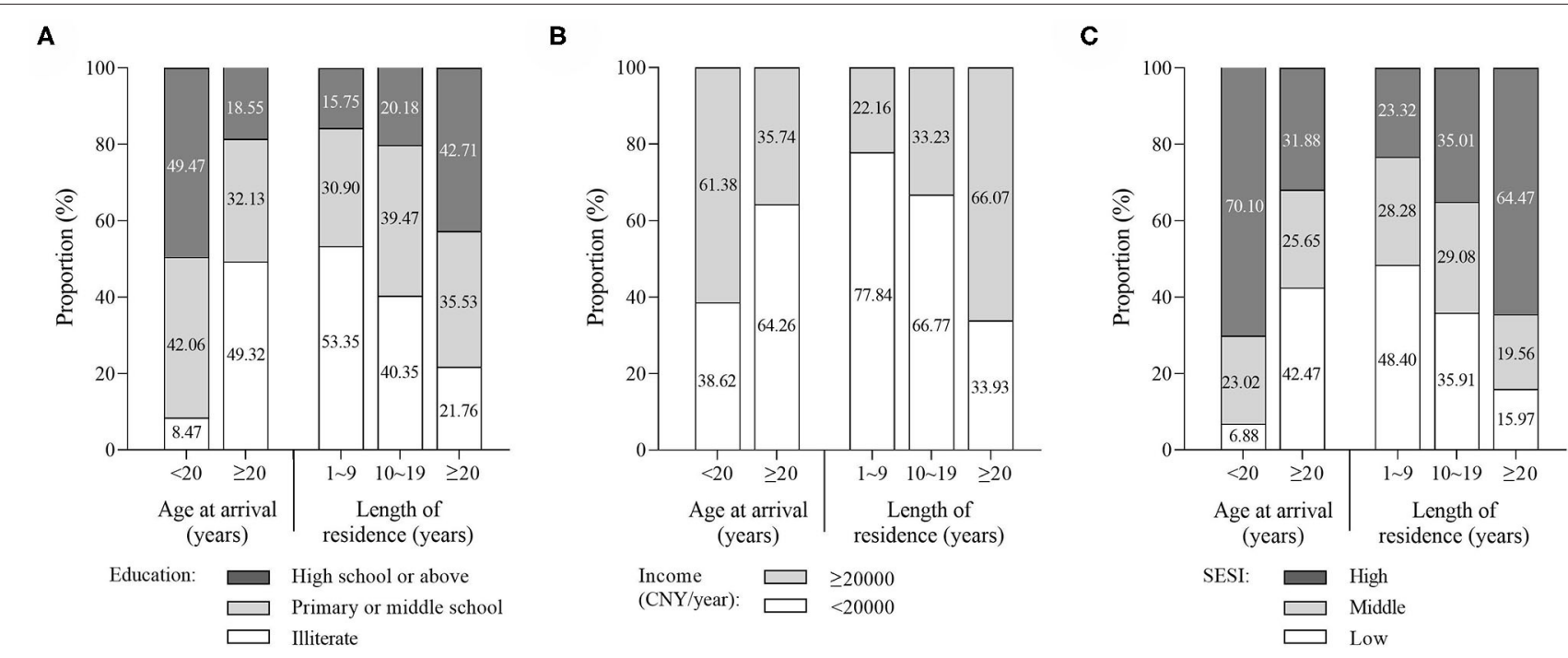

FIGURE 1 | Disparities in education (A), income (B), and socioeconomic status index (SESI) (C) by age at arrival and length of residence.

likely to participant in leisure-time exercise. The mean BMI of the two groups was not significantly different, while the crude prevalence of overweight/obesity was higher in $\geq 20$ years at arrival than that in their counterparts. Among the groups of length of residence, respondents with $\geq 20$ years of residence had the oldest age, the most proportion of current smoking, current drinking, light occupational physical activity, and heavy leisure-time exercise. The mean BMI and crude prevalence of overweight/obesity increased considerably with the duration of residence in urban areas.

Bar chart (Figure 1) clearly shows the disparities in socioeconomic status of Yi migrants with different age at arrival and length of residence. Compared to their counterparts of $\geq 20$ years at arrival, migrants of $<20$ years at arrival were better educated, had higher income, and had a higher proportion of high SESI level. Of the migrants with $<20$ years at arrival, nearly half had the high school education level or above, while in respondents with $\geq 20$ years of arrival, nearly half of them were uneducated. In migrants of $<20$ years at arrival, the proportion of high-income level $(\geq 20,000 \mathrm{CNY} /$ year $)$ was $61.38 \%$, corresponding $35.74 \%$ in migrants of $\geq 20$ years at arrival. Combining education and income, most respondents with $<20$ years of arrival had high SESI level, and only $6.88 \%$ of them had low SESI level. The distribution of SESI in migrants of $\geq 20$ years at arrival was relative balanced. There was an apparent tendency that the distribution of socioeconomic status changed with length of residence. The proportions of high education level, high income, as well as high SESI level raised with the length of residence increased.

Table 2 reports the estimated coefficients and odds ratios for the multiple regression models assessing the relationship between socioeconomic status and outcomes. These models used the full sample, which means the age at arrival was include as a covariate. The results reveal that after adjusting for potential confounding factors including age, gender, age at arrival, length of residence,
TABLE 2 | Effects of socioeconomic status on BMl and overweight/obesity by multiple regression models.

\begin{tabular}{|c|c|c|c|c|}
\hline & \multicolumn{2}{|c|}{ BMI* } & \multicolumn{2}{|c|}{ Overweight/obesity** } \\
\hline & $\beta$ & $95 \% \mathrm{Cl}$ & OR & $95 \% \mathrm{Cl}$ \\
\hline \multicolumn{5}{|l|}{ Model 1} \\
\hline \multicolumn{5}{|l|}{ Education } \\
\hline Illiterate & 0.00 (ref) & - & 1.00 (ref) & - \\
\hline Primary or middle school & -0.10 & $-0.68,0.49$ & 0.86 & $0.76,0.98$ \\
\hline High school or above & 0.16 & $-0.60,0.91$ & 1.12 & $1.00,1.26$ \\
\hline \multicolumn{5}{|l|}{ Income (CNY/year) } \\
\hline$<20,000$ & 0.00 (ref) & - & 1.00 (ref) & - \\
\hline$\geq 20,000$ & 0.17 & $-0.38,0.71$ & 1.06 & $0.88,1.28$ \\
\hline \multicolumn{5}{|l|}{ Model 2} \\
\hline \multicolumn{5}{|l|}{ SESI } \\
\hline Low & 0.00 (ref) & - & 1.00 (ref) & - \\
\hline Middle & -0.10 & $-0.71,0.51$ & 0.91 & $0.73,1.15$ \\
\hline High & 0.14 & $-0.50,0.78$ & 1.04 & $0.90,1.21$ \\
\hline
\end{tabular}

${ }^{*}$ General linear regression models were applied.

**Logistic regression models were applied.

Models adjusted for age, gender, smoking, drinking, occupational physical activity, leisuretime exercise, age at arrival, and length of residence.

etc., significant association was only found between education with overweight/obesity.

As significant interaction terms were detected between SES and age at arrival $(P<0.0001$ for education, $P=0.0007$ for income, and $P<0.0001$ for SESI, respectively), the sample was stratified by age at arrival to show different patterns of BMI and overweight/obesity between groups. Figure 2 graphs how the effects of SES on outcomes varied by age at arrival. Figure $2 \mathrm{~A}$ shows that the trends of adjusted BMI with socioeconomic status were opposite in the two age 

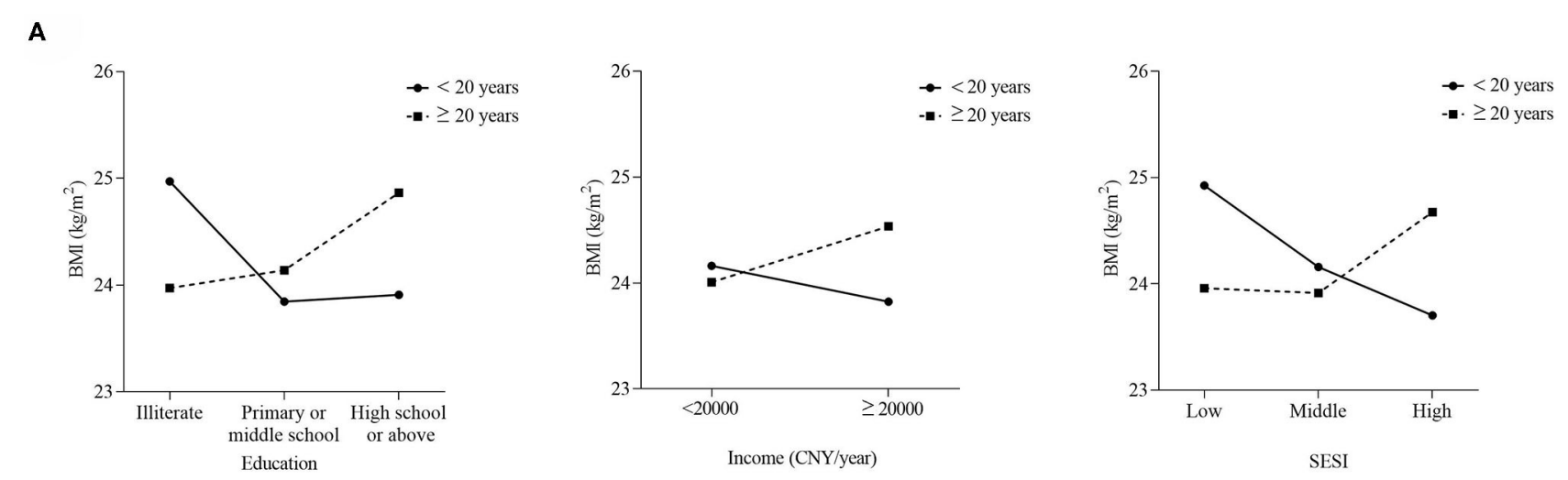

B
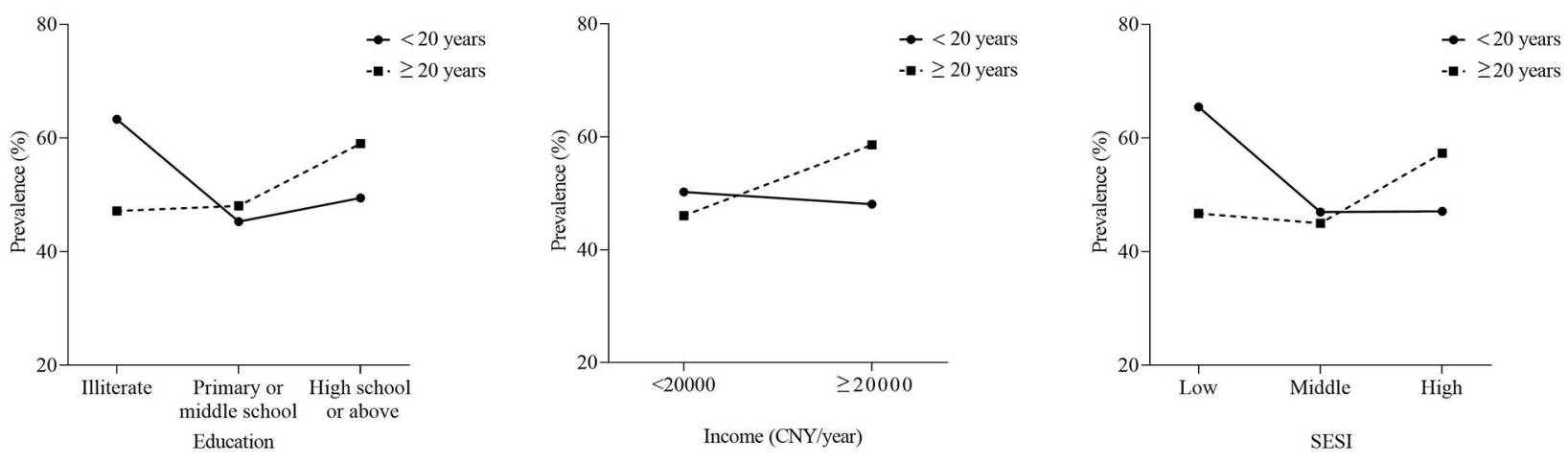

FIGURE 2 | Trends of BMI (A) and overweight/obesity prevalence (B) with socioeconomic status by age at arrival. BMI was adjusted for age, gender, smoking, drinking, occupational physical activity, leisure-time exercise, and length of residence; prevalence was age and sex standardized.

at arrival groups. In migrants of $<20$ years at arrival, the highest BMI presented to the illiterate, $<20,000 \mathrm{CNY} /$ year, and low SESI groups. Conversely, in migrants of $\geq 20$ years at arrival, the trends between socioeconomic status and BMI shifted from negative to positive. The highest BMI presented to the high school or above, $\geq 20,000 \mathrm{CNY} /$ year, and high SESI groups. Similar patterns of overweight/obesity prevalence between the two groups were also displayed in Figure 2B.

Forest plot (Figure 3) shows the association between socioeconomic status and overweight/obesity in stratification analysis. In migrants of $<20$ years at arrival, there was a negative association of education and SESI with overweight/obesity. Compared to illiterate, odds ratios for middle and high education level were $0.47(0.42-0.52)$ and $0.46(0.35-0.60)$. Compared to low SESI level, odds ratios for middle and high SESI groups were $0.50(0.40-0.62)$ and 0.34 (95\% CI: 0.14-0.86). In contrast, in migrants of $\geq 20$ years at arrival, higher SES level was positively related to overweight/obesity risk. Compared to illiterate group, odds ratio for high school and above was 1.84 (95\% CI: $1.45-2.34)$. The odds ratio for higher income group was 1.23 (1.01-1.50) compared to lower income group. The odds ratio for high SESI level was 1.66 (95\% CI: 1.31-2.10) relative to low SESI level.

\section{DISCUSSION}

In this population-based cross-sectional study, socioeconomic status was found as an independent determinant of overweight/obesity in Yi rural-to-urban migrants in China. The results showed that the relationship of SES with overweight/obesity in Yi rural-to-urban migrants was modified by age at arrival, which was found out that without stratification, the association was not significant especially for income and SESI. This study revealed that in Yi migrants of $<20$ years at arrival, SES was negatively associated with overweight/obesity, controlling for age, gender, smoking, drinking, occupational physical activity, leisure-time exercise, and length of residence. On the contrary, in those of $\geq 20$ years at arrival, higher SES groups were related to increased risk.

As a widely recognized risk factor, socioeconomic status and its relationship with obesity has been explored in numerous studies (17-20). The indicators used to reflect SES as well as their classifications in these studies varied, and the mainly used variables were education, income, and occupation (7-9). In the present study, two of these conventional indicators were selected (education and income). We did not include occupation because the age range of the participants was wide ( $20-80$ years), which means the older part of the study population were mostly 


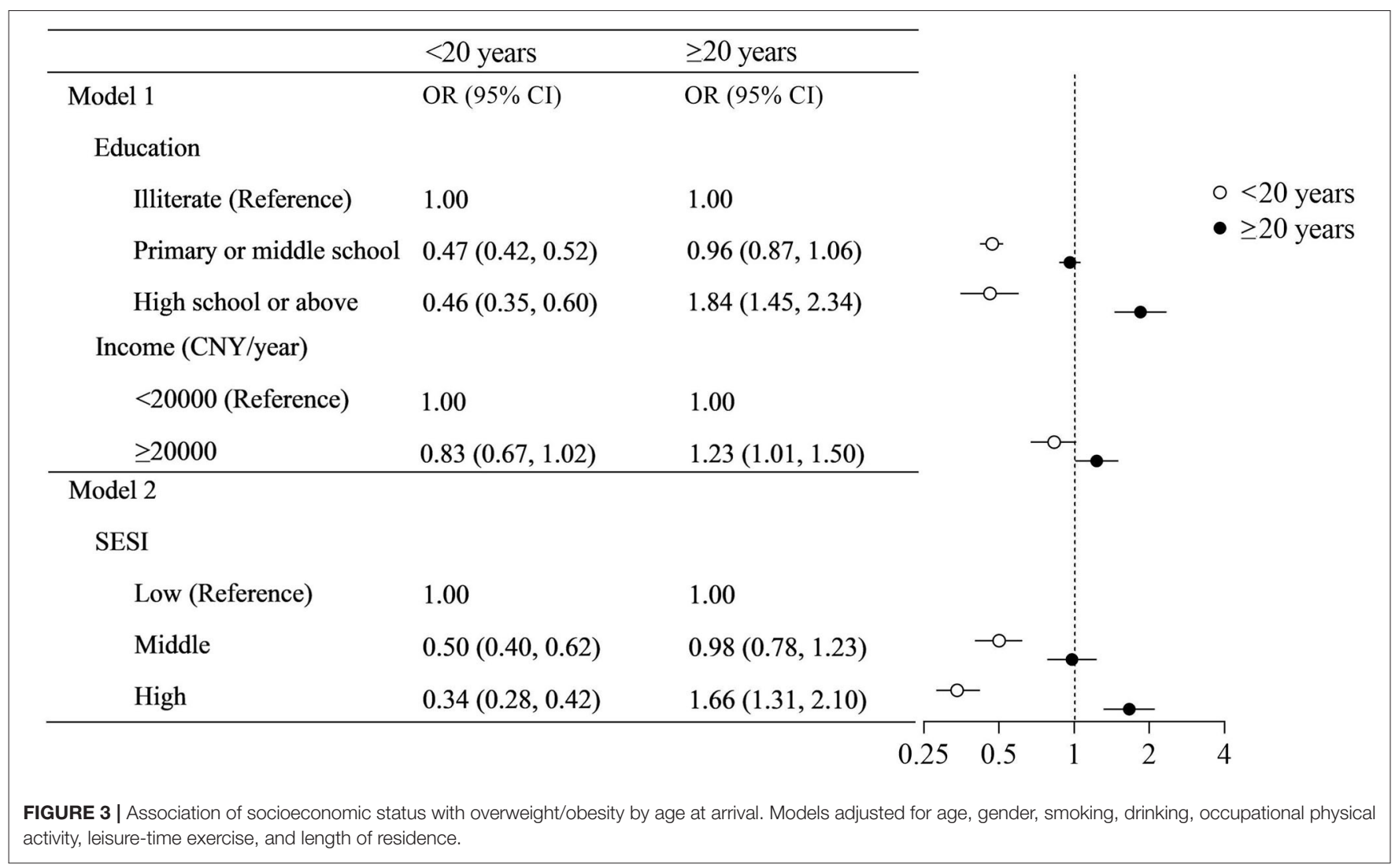

retired or unemployed. Besides, there is a correlation among the SES indicators, and the variation in occupation can be largely explained by education and income $(21,22)$. As to income, to some extent, it can reflect the accessibility to food and health care services, and the fact is, part of rural-to-urban migrants especially the elderly was not engaged in a stable work to earn a monthly income. So, we conducted a conservative classification by the median value. As opposed to income and occupation, education is acquired in early life stage and extending throughout lifetime. Among these SES indicators, education is considered as the most stable component to reflect health awareness, health care ability, and lifestyle patterns, etc. $(22,23)$. In this study, a new comprehensive indicator (socioeconomic status index, SESI) was composited by education and income, in which education accounted for a heavier weight (24). The results suggested that SESI was a stable variable and did not altered the relationship of SES with overweight/obesity in the study population.

Previous studies concluded that the relationship between SES and obesity differed by the country's level of development, which means that positive associations between SES and obesity were more common in less developed countries, while inversed association were commonly found in developed countries (25). Following the modernization and dramatic economic development over the past decades, China has experienced a transition from the history of undernutrition to a rapid increase in obesity (26). The patterns of SES-obesity relationship can be traced across the different stage of economic development. A study explored the discernible patterns of obesity epidemic over time and grouped the obesity transition into conceptual stages (27), among which China is experiencing the stage characterized by narrowing gap or a reversal of socioeconomic differences in obesity. A study from the urban and suburban region in north China showed that higher monthly income and education were related to decreased odds of abdominal overweight/obesity (9). Another study focusing on the rural residents in northwest China revealed that in men, the risk of overweight/obesity and abdominal obesity were higher in the high SES groups, but women with a high level of education were less likely to have overweight/obesity than those with a low level of education (8).

The pathways explaining the relationship of SES and obesity are multiple, including increased energy and fat consumption $(28,29)$ and decreased density of physical activity $(30-32)$. A systematic review which evaluated the behavioral risk factors in low-income and lower-middle-income countries found that behaviors, such as alcohol drinking, tobacco use, physical activity, and food consumption (e.g., fruit, fats, processed food, etc.) were at difference between low and high SES groups (30). The novel findings in this study are notable for several reasons. First, to our knowledge, evaluations on the association of SES and obesity in Chinese rural-to-urban migrants are limited. Second, this study showed that there were significant disparities on SES by age at arrival and length of residence in migrants. Finally, this study stratified the rural-to-urban migrants and found opposed association of SES and overweight/obesity by age at arrival. One 
of the main points to explain the differed association by age at arrival is educational attainment (33). In their early life stage, the two Yi migrant groups were educated in different environment. The rural-urban disparities in education quality may lead to the differences in health literacy and the accessibility to health information (34). Of those $\geq 20$ years at arrival, with the SES level raising, they may be more likely to change their dietary habit and increase the high-fat energy-dense food intake. On the contrary, those moving from rural to urban areas in childhood were more adapted to the urbanized lifestyle, reflecting in the adherence to healthier behavior factors like leisure time physical activity.

One major limitation of this study is lack of the collection on dietary data. Obtaining reliable and accuracy dietary information in a large-scale population-based field survey is a big challenge, this part was not included in the study. As the socioeconomic is closely related to dietary habit, the bias due to diet cannot be adjusted. In the future, details such as food preference are expected in field work.

In conclusion, the results suggested that the SES-obesity relationship was modified by age at arrival in rural-tourban Yi migrants. Positive association between SES and overweight/obesity was found in those $\geq 20$ years at arrival, while inversed association was found in those $<20$ years at arrival. This study calls for the urgent need to improve education attainment especially health literacy. We also emphasize the healthy lifestyle adherence in rural-to-urban migrants.

\section{REFERENCES}

1. Di Angelantonio E, Bhupathiraju SN, Wormser D, Gao P, Kaptoge S, de Gonzalez $\mathrm{AB}$, et al. Body-mass index and all-cause mortality: individualparticipant-data meta-analysis of 239 prospective studies in four continents. Lancet. (2016) 388:776-86. doi: 10.1016/S0140-6736(16)30175-1

2. Blüher M. Obesity: global epidemiology and pathogenesis. Nat Rev Endocrinol. (2019) 15:288-98. doi: 10.1038/s41574-019-0176-8

3. Albuquerque D, Nobrega C, Manco L, Padez C. The contribution of genetics and environment to obesity. Br Med Bull. (2017) 123:159-73. doi: 10.1093/bmb/ldx022

4. Wang Y, Beydoun MA. The obesity epidemic in the United Statesgender, age, socioeconomic, racial/ethnic, and geographic characteristics: a systematic review and meta-regression analysis. Epidemiol Rev. (2007) 29:628. doi: 10.1093/epirev/mxm007

5. Drewnowski A, Moudon AV, Jiao J, Aggarwal A, Charreire H, Chaix B. Food environment and socioeconomic status influence obesity rates in Seattle and in Paris. Int J Obes (Lond). (2014) 38:306-14. doi: 10.1038/ijo.2013.97

6. Dinsa GD, Goryakin Y, Fumagalli E, Suhrcke M. Obesity and socioeconomic status in developing countries: a systematic review. Obes Rev. (2012) 13:106779. doi: 10.1111/j.1467-789X.2012.01017.x

7. Pampel FC, Denney JT, Krueger PM. Obesity, SES, and economic development: a test of the reversal hypothesis. Soc Sci Med. (2012) 74:1073-81. doi: 10.1016/j.socscimed.2011.12.028

8. Pei L, Cheng Y, Kang Y, Yuan S, Yan H. Association of obesity with socioeconomic status among adults of ages 18 to 80 years in rural Northwest China. BMC Public Health. (2015) 15:160. doi: 10.1186/s12889-015-1503-1

9. Zhang $\mathrm{H}, \mathrm{Xu} \mathrm{H}$, Song $\mathrm{F}, \mathrm{Xu} \mathrm{WL}$, Pallard-Borg S, Qi XY. Relation of socioeconomic status to overweight and obesity: a large populationbased study of Chinese adults. Ann Hum Biol. (2017) 44:495-501. doi: 10.1080/03014460.2017.1328072

10. Chan F, Adamo S, Coxson P, Goldman L, Gu D, Zhao D, et al. Projected impact of urbanization on cardiovascular disease in China. Int J Public Health. (2012) 57:849-54. doi: 10.1007/s00038-012-0400-y

\section{DATA AVAILABILITY STATEMENT}

The datasets generated or analyzed for this study are available from the corresponding author on reasonable request.

\section{ETHICS STATEMENT}

The studies involving human participants were reviewed and approved by the institutional review board of Institute of Basic Medical Sciences, Chinese Academy of Medical Sciences. The patients/participants provided their written informed consent to participate in this study.

\section{AUTHOR CONTRIBUTIONS}

GS designed the study and supervised data collection. YW analyzed the data, interpreted results, and drafted the manuscript. LP, SW, HY, FY, ZL, and ZY participated in data collection. HH critically reviewed the manuscript. All authors have approved the submitted versions.

\section{FUNDING}

This work was supported by grants from National Natural Science Foundation of China (Grant No. 81273158).

11. He J, Klag MJ, Whelton PK, Chen JY, Mo JP, Qian MC, et al. Migration, blood pressure pattern, and hypertension: the Yi Migrant Study. Am J Epidemiol. (1991) 134:1085-101. doi: 10.1093/oxfordjournals.aje.a116012

12. Wang B, Wei D, Wang C, Zhang J, Pan L, Ma M, et al. Prevalence of dyslipidemia and associated factors in the Yi farmers and migrants of Southwestern China. Atherosclerosis. (2012) 223:512-8. doi: 10.1016/j.atherosclerosis.2012.06.009

13. Wang Y, Pan L, Wan S, Yi H, Yang F, He H, et al. Increasing prevalence of overweight and obesity in Yi farmers and migrants from 2007 to 2015 in China: the Yi migrant study. BMC Public Health. (2018) 18:659. doi: 10.1186/s12889-018-5577-4

14. He H, Pan L, Pa L, Cui Z, Ren X, Wang D et al. Data resource profile: the China national health survey (CNHS). Int J Epidemiol. (2018) 47:1734-5f. doi: 10.1093/ije/dyy151

15. Zhou BF. Predictive values of body mass index and waist circumference for risk factors of certain related diseases in Chinese adults-study on optimal cut-off points of body mass index and waist circumference in Chinese adults. Biomed Environ Sci. (2002) 15:83-96. doi: 10.1046/j.1440-6047.11.s8.9.x

16. Cole SR. Analysis of complex survey data using SAS. Comput Methods Programs Biomed. (2001) 64:65-9. doi: 10.1016/S0169-2607(00)00088-2

17. Mclaren L. Socioeconomic status and obesity. Epidemiol Rev. (2007) 29:29-48. doi: 10.1093/epirev/mxm001

18. Corsi DJ, Subramanian SV. Socioeconomic gradients and distribution of diabetes, hypertension, and obesity in India. JAMA Netw Open. (2019) 2:e190411. doi: 10.1001/jamanetworkopen.2019.0411

19. Pigeyre M, Rousseaux J, Trouiller P, Dumont J, Goumidi L, Bonte D, et al. How obesity relates to socio-economic status: identification of eating behavior mediators. Int J Obes (Lond). (2016) 40:1794-801. doi: 10.1038/ijo.2016.109

20. Caldwell AE, Sayer RD. Evolutionary considerations on social status, eating behavior, and obesity. Appetite. (2019) 132:238-48. doi: 10.1016/j.appet.2018.07.028

21. Fujishiro K, Xu J, Gong F. What does "occupation” represent as an indicator of socioeconomic status? exploring occupational prestige and health. Soc Sci Med. (2010) 71:2100-7. doi: 10.1016/j.socscimed.2010.09.026 
22. Miech RA, Hauser RM. Socioeconomic status and health at midlife. A comparison of educational attainment with occupation-based indicators. Ann Epidemiol. (2001) 11:75-84. doi: 10.1016/S1047-2797(00)00079-X

23. Thurston RC, Kubzansky LD, Kawachi I, Berkman LF. Is the association between socioeconomic position and coronary heart disease stronger in women than in men? Am J Epidemiol. (2005) 162:57-65. doi: 10.1093/aje/kwi159

24. Xie C, Qin C, Wang G, et al. Relationship between socioeconomic status and the prevalence of cardiovascular disease among retired residents living in a community, Shanghai. Zhonghua liu xing bing xue za zhi. (2014) 35:500-4. doi: 10.3760/cma.j.issn.0254-6450.2014.05.007

25. Cohen AK, Rai M, Rehkopf DH, Abrams B. Educational attainment and obesity: a systematic review. Obes Rev. (2013) 14:989-1005. doi: 10.1111/obr.12062

26. Gordon-Larsen P, Wang H, Popkin BM. Overweight dynamics in Chinese children and adults. Obes Rev. (2014) 15(Suppl. 1):37-48. doi: $10.1111 /$ obr.12121

27. Jaacks LM, Vandevijvere S, Pan A, McGowan CJ, Wallace C, Imamura F, Mozaffarian D, et al. The obesity transition: stages of the global epidemic. Lancet Diabetes Endocrinol. (2019) 7:231-40. doi: 10.1016/S2213-8587(19)30026-9

28. Costa BVL, Menezes MC, Oliveira CDL, Mingoti SA, Jaime P, Caiaffa WT, et al. Does access to healthy food vary according to socioeconomic status and to food store type? An ecologic study. BMC Public Health. (2019) 19:775. doi: 10.1186/s12889-019-6975-y

29. Best M, Papies EK. Lower socioeconomic status is associated with higher intended consumption from oversized portions of unhealthy food. Appetite. (2019) 140:255-68. doi: 10.1016/j.appet.2019.05.009

30. Allen L, Williams J, Townsend N, Mikkelsen B, Roberts N, Foster $\mathrm{C}$, et al. Socioeconomic status and non-communicable disease behavioural risk factors in low-income and lower-middle-income countries: a systematic review. Lancet Global Health. (2017) 5:e277-89. doi: 10.1016/S2214-109X(17)30058-X

31. Schultz WM, Kelli HM, Lisko JC, Varghese T, Shen J, Sandesara $\mathrm{P}$, et al. Socioeconomic status and cardiovascular outcomes: challenges and interventions. Circulation. (2018) 137:2166-78. doi: 10.1161/CIRCULATIONAHA.117.029652

32. Adler NE, Newman K. Socioeconomic disparities in health: pathways and policies. Health Aff (Project Hope). (2002) 21:60-76. doi: $10.1377 /$ hlthaff.21.2.60

33. Kim TJ, Roesler NM, von dem Knesebeck O. Causation or selectionexamining the relation between education and overweight/obesity in prospective observational studies: a meta-analysis. Obes Rev. (2017) 18:66072. doi: $10.1111 /$ obr.12537

34. Hagman E, Danielsson P, Brandt L, Svensson V, Ekbom A, Marcus C. Childhood obesity, obesity treatment outcome, and achieved education: a prospective cohort study. J Adolesc Health. (2017) 61:508-13. doi: 10.1016/j.jadohealth.2017.04.009

Conflict of Interest: The authors declare that the research was conducted in the absence of any commercial or financial relationships that could be construed as a potential conflict of interest.

Copyright (c) 2020 Wang, Pan, Wan, Yi, Yang, He, Li, Yong and Shan. This is an open-access article distributed under the terms of the Creative Commons Attribution License (CC BY). The use, distribution or reproduction in other forums is permitted, provided the original author(s) and the copyright owner(s) are credited and that the original publication in this journal is cited, in accordance with accepted academic practice. No use, distribution or reproduction is permitted which does not comply with these terms. 